\title{
Proceeding
}

Supplementary Issue: Winter Conferences of Sports Science. Costa Blanca Sports Science Events, 22-23 March 2021. Alicante, Spain.

\section{Intra-articular hyaluronic acid injections and oral collagen supplementation for knee OA: A case report of an elite female soccer player}

\author{
DOMIZIANO TARANTINO $\triangle$, FELICE SIRICO, BRUNO CORRADO, CARLO RUOSI \\ Department of Public Health, University Federico II of Naples, Italy
}

\begin{abstract}
Soccer players are susceptible to repeated trauma that could lead to a precocious development of knee osteoarthritis (OA). Intra-articular hyaluronic acid (IA-HA) injections have been proposed as a valid treatment for knee OA. Objectives: To describe the effects of IA-HA injections and oral collagen supplementation in a female soccer goalkeeper playing in Italian Women's Serie A with secondary OA in her knee. Design: Case report. Setting: The athlete underwent three IA-HA injections (1 per week for 3 weeks in a row) together with oral collagen supplementation for one month. Treatment outcomes were evaluated using five scoring scales. Results: One week after the first IA-HA injection all the scores improved. One week after the second injection, compared with the first week, two scores improved, two remained the same, and one worsened. One week after the third injection, compared with the second week, all the scores worsened. At one month, compared with the third week, one score remained the same and all the others worsened. From baseline to one month, three scores improved, one remained the same, and one worsened. Conclusions: In our study, IA-HA injections and oral collagen supplementation showed short-term effects on pain and functional impairment for knee OA.

Keywords: Knee osteoarthritis; Intra-articular therapy; Hyaluronic acid; Oral collagen supplementation; Female soccer player.

Cite this article as:

Tarantino, D., Sirico, F., Corrado, B., \& Ruosi, C. (2021). Intra-articular hyaluronic acid injections and oral collagen supplementation for knee OA: A case report of an elite female soccer player. Journal of Human Sport and Exercise, 16(3proc), S1384-S1394. https://doi.org/10.14198/ihse.2021.16.Proc3.54
\end{abstract}

Corresponding author. Department of Public Health, University Federico II of Naples, Italy.

E-mail: domiziano22@gmail.com

Abstract submitted to: Winter Conferences of Sports Science. Costa Blanca Sports Science Events, 22-23 March 2021. Alicante, Spain.

JOURNAL OF HUMAN SPORT \& EXERCISE ISSN 1988-5202.

(C) Faculty of Education. University of Alicante.

doi:10.14198/jhse.2021.16.Proc3.54 


\section{INTRODUCTION}

Soccer is a high-contact and high-impact sport in which players often develop acute or chronic injuries, particularly potential injuries in the joints (Wu et al., 2017). Repeated small traumas involving joints may result in cartilage lesions and joint instability, concurring to a precocious development of knee osteoarthritis (OA) (Aicale et al., 2018; Dvorak, 2011; Gouttebarge et al., 2014; Krajnc et al., 2010).

Knee $\mathrm{OA}$ is a common, slowly progressive and often disabling joint disorder among adults characterized by cartilage degeneration and inflammation that may result in impaired activity and daily function and early retirement (Altman et al., 2016; Bannuru et al., 2014; Cheng et al., 2012). Joint pathologies, such as meniscal tear, ACL o PCL injury or valgus-varus axis deviation, can cause symptoms and lead to a rapid progression of cartilage injury (Aune et al., 2014).

Several studies have reported how sports such as soccer may represent a cause of early-onset OA, especially after major traumas in the dominant or nondominant leg, involving usually knee, ankle, and hip joints (Krajnc et al., 2010). Several studies have reported that up to 19-29\% of soccer players develop OA, which seriously affects their careers (Drawer and Fuller, 2001). Active soccer players may experience a limitation in their activity due to knee pain, especially after sporting activity (Migliore et al., 2018). Athletes affected by knee pain usually continue practicing their sports, often with difficulties and decrease in quality of performance (Migliore et al., 2018). Therefore, the prevention of knee injuries, the maintenance of knee joints and the early detection and diagnosis of knee OA are crucial for soccer players (Elleuch et al., 2008; Takeda et al., 2011; Tarantino and Brancaccio, 2019; Wu et al., 2017).

No generally accepted therapy is available that alters the course of $O A$, and the therapy is directed at reducing pain and improving function (Altman et al., 2016; Bannuru et al., 2014). Medications including nonsteroidal anti-inflammatory drugs (NSAIDs), acetaminophen, duloxetine, opioids, topical NSAIDs and capsaicin are effective in reducing symptoms (McAlindon et al., 2014). Intra-articular injections can be carried out using corticosteroid (da Costa et al., 2016), hyaluronic acid (HA) (He et al., 2017), ozone (Raeissadat, et al., 2018), plasma rich in growth factor (Sánchez et al., 2012), and platelet-rich plasma (Ayhan et al., 2014). Most of these treatments are able to reduce pain in the short-term, after single-administration both in intraarticular and peri-articular musculoskeletal problems (Vazquez et al., 2019; Sirico et al., 2017). Physical therapies have also been investigated regarding knee OA (Nouri et al., 2019; Raeissadat et al., 2018).

In knee OA, HA is reduced both in molecular weight and concentration. For this reason, IA-HA is nowadays the most common treatment for knee OA or cartilage degeneration, and it has been proposed to provide shock absorptive, chondroprotective, and anti-inflammatory effects within the knee (Creamer et al., 1994; Maheu et al., 2019; Moreland, 2003; Wu et al., 2017). HA also plays a role in traumatic energy dissipation and lubrication and it is capable of decreasing nerve impulses related to OA pain. (Bahrami et al., 2020; Tasciotaoglu and Oner, 2003). Evidence suggests that HA has significant short-term efficacy ( $\leq 6$ months) for treating knee OA pain. IA-HA therapy was found to be an effective and safe short-term treatment option for pain due to knee OA, resulting to be more efficacious than NSAIDs, IA-corticosteroids and IA-placebo (Bannuru et al., 2015). IA-HA treatment showed significant improvement from baseline pain (Miller and Block, 2013); however, the relative effectiveness of the long-term use of IA-HA through repeat courses of treatment remains to be determined.

Several studies have reported on the good efficacy and safety profiles of intra-articular hyaluronic acid (Baltzer et al., 2009; Bannuru et al., 2014; Marshall, 2003; Reid, 2013; Roque et al., 2013). As a side effect, 
several studies have reported how in the hours or days following the intra-articular injection of hyaluronic acid some patients may experience a transient pain in the injected joint (Miller and Block, 2013). Usually, this pain is reported as transient and regresses without any need of medications (Migliore et al., 2018).

The use of intra-articular hyaluronic acid has not been reported for professional athletes, so data regarding the use of hyaluronic acid in professional athletes are still lacking (Migliore et al., 2018). Furthermore, to our knowledge no studies evaluated the effects of IA-HA injections in female soccer players.

In this case-report study, we aimed to investigate the effects of IA-HA injections and oral collagen supplementation in a female soccer goalkeeper playing in Italian Women's Serie A league with secondary knee OA with symptomatic knee pain, and to establish whether they may represent a suitable therapeutic option for managing secondary $\mathrm{OA}$.

\section{MATERIAL AND METHODS}

\section{Participant}

The player was a female 26-year-old (at the time of treatment) goalkeeper (height $174 \mathrm{~cm}$, body mass $69 \mathrm{~kg}$ ) playing in the Italian Women's Serie A league (the highest level of the Italian Women soccer system).

During the two weeks before the beginning of the therapy, she was complaining of pain in the affected knee, however the symptoms were not consistent and allowed her to train and play matches without limitations. The player gave a written informed consent to participate in the study.

\section{Injury history}

The athlete suffered from a first ACL tear at the left knee in June 2014. She had an ACL tear and no concurrent injury occurred. The injury followed a slide tackle from an opponent with our athlete's leg getting caught during a game. The player underwent surgery on July 4, 2014.

A second ACL tear, along with medial and lateral menisci tears, again at her left knee occurred after an improper change of direction during a game with her National Team. An ACL revision was needed and she underwent surgery on December 26, 2017. The athlete also underwent partial meniscectomy of medial and lateral menisci on February 26, 2019.

\section{Diagnosis and first-line therapy}

After an accurate clinical evaluation, the athlete started a first-line therapy with cryotherapy and NSAIDs (ibuprofen), but with poor results. Then she underwent a magnetic resonance imaging (MRI) four days before the beginning of the therapy with IA-HA injections and oral collagen supplementation. The main findings at the MRI were:

- The ACL graft was continuous and correctly inserted.

- Moderate secondary OA.

- Degeneration of the medial meniscus that appeared slightly thinned.

- Mucoid degeneration of the lateral meniscus.

\section{Intra-articular hyaluronic acid injections and oral collagen supplementation}

The medical staff of the club the athlete plays for, in agreement with the orthopaedic surgeon who performed the three surgeries, decided to start a combined treatment protocol with IA-HA injections and oral collagen supplementation as follow: 
- IA-HA injections: 1 injection a week for 3 weeks in a row.

- Oral collagen supplementation: 1 month of treatment.

The HA used for this treatment was a high molecular weight hyaluronic acid $30 \mathrm{mg} / 2 \mathrm{ml}$ each. High molecular weight hyaluronic acids derived from biological fermentation were found to be superior in efficacy and safety if compared to low molecular weight hyaluronic acids (Altman et al., 2016; Hummer et al., 2020).

The three IA-HA injections regimen was adopted since it has been demonstrated that repeated courses of IA-HA injections are an effective and safe treatment for knee OA, providing the greatest benefit when compared to IA-Saline with respect to pain improvement (Altman et al., 2018; Concoff et al., 2017).

The oral collagen supplementation was carried out using $10 \mathrm{~g}$ of hydrolysed collagen for three days, then a $5 \mathrm{~g}$ of hydrolysed collagen for other three days, then an oral supplement with $5 \mathrm{~g}$ of collagen peptides, calcium and vitamin $D$ for six days and, finally, an oral supplement with $2 \mathrm{~g}$ of hydrolysed collagen, $300 \mathrm{mg}$ of glucosamine and $300 \mathrm{mg}$ of chondroitin sulphate.

Oral collagen supplementation was found to lead to significant improvements in patients with moderate knee $\mathrm{OA}$ after short daily treatments with oral HA preparations, compared to placebo-treated controls (Guadagna et al., 2018). Current clinical data on oral HA products for the treatment of mild to moderate knee OA are promising, and cumulative findings appeared to support a more favourable role than not for collagen supplements in efforts to safely reduce mild to moderate OA pain of the hand, hip or knee and to improve physical function at short term (Aghamohammadi et al., 2020; Honvo et al., 2020; Liu et al., 2018; Marks, 2020), although the quality of evidence is very low (Liu et al., 2018).

\section{Outcome evaluation}

The evaluation of the treatment's outcomes was carried out using five scoring scales:

- Visual analogue scale (VAS): a self-administered tool used for pain measurement in a $10 \mathrm{~cm}$ (so from 0 to 10) horizontal line, where 0 is no pain, 5 is moderate pain, and 10 is extreme pain (Crichton, 2001);

- Tegner Lysholm knee scoring scale: it assesses symptoms during daily activities, with a maximum score of 100 (Tegner and Lysholm, 1985). A score less than 65 indicates a poor condition, a fair one between 65 and 83, a good condition between 84 and 90 , and an excellent condition if the score is more than 90 (Mitsou et al., 1990);

- Knee Injury and Osteoarthritis Outcome Score (KOOS): a self-administered questionnaire that assesses five outcomes: pain, symptoms, activities of daily living, sport and recreation function, and knee-related quality of life. Scores are transformed to a 0-100 scale, with 0 representing extreme knee problems and 100 representing no knee problems (Roos et al., 1998);

- International Knee Documentation Committee (IKDC) score: it is a knee-specific measure of symptoms, function, and sports activity (Irrgang et al., 2001). Scores for each item are summed to give a total score, then the total score is calculated as (sum of items)/(maximum possible score) $x$ 100 , to give a total score of 100 . Possible score range $0-100$, where 100 represents no limitation with daily or sporting activities and the absence of symptoms (Collins et al., 2011);

- Modified Cincinnati Knee Rating System (mCKRS): the questionnaire is composed by multiple parts: symptoms, sports activity, and activities of daily living scales. The mCKRS scores range from 6 to 100 (best function) (Agel and LaPrade, 2009; Noyes et al., 1989). 
Clinical evaluation and submission of questionnaires were made face-to-face at baseline (which was just before the first IA-HA injection), then before the other two injections, and then one and two weeks after the last injection.

\section{Post-therapy considerations}

After the first IA-HA injection, the athlete had headache, dizziness and body fatigue for two days. After the second injection, she felt a sensation of discomfort in the knee. After the third injection, she did not experience any adverse effect.

\section{Physical activity performed during the treatment period}

After the first IA-HA injection, there was no match during the weekend, so the athlete totally rested for three days, returning to training on the fourth day after the injection.

After the second injection, the athlete performed a personalised training (especially upper body and core, avoiding weight-bearing on the knee) the day after, then she took part at the pre-match warm-up (but she did not play) on the second day after the injection, then she rested on the third day after the injection, and returned to full training on the fourth day after the injection.

After the third injection, the athlete attended the pre-match training the day after the injection and played the entire match two days after the injection.

The day after the match, the athlete returned to her home country since there were no games scheduled for one month so, during the first week after the third injection, she went running, made some body weight exercises, and worked with bands.

During the second week after the third injection (so at the end of the one-month treatment), she performed some on the field soccer training, but it was limited some days due to knee pain. She also performed some upper body work and body weight exercises, and stationary bike training.

\section{RESULTS}

A summary of the scores collected during the treatment period is reported in Table 1.

Table 1. Questionnaires' scores taken during the treatment period.

\begin{tabular}{lccccc}
\hline & $\begin{array}{c}\text { Baseline (before } \\
\text { 1st injection) }^{\text {Binjection }}\end{array}$ & $\begin{array}{c}\text { Before } \\
\text { injection }\end{array}$ & $\begin{array}{c}\text { Before 3rd } \\
\text { injection }\end{array}$ & $\begin{array}{c}\text { 1 week after } \\
\text { 3rd injection }^{\text {2 }}\end{array}$ & $\begin{array}{c}\text { 2 weeks after 3rd } \\
\text { injection (1 month) }\end{array}$ \\
\hline VAS & 7 & 4.5 & 6 & 7.5 & 8 \\
Tegner- & 46 & 79 & 79 & 61 & 61 \\
Lysholm & 46 & 75 & 82.4 & 71.3 & 67.5 \\
KOOS & 60.1 & 67.8 & 67.8 & 62.1 & 57.5 \\
IKDC & 57.5 & 80 & 92 & 80 & 70 \\
mCKRS & 68 & & & &
\end{tabular}

The VAS score improved from the baseline to before the second injection by $36 \%$, then it started to increase, reporting a worsening of the $33 \%$ before the third injection, so then increased even more overcoming the baseline score by $7 \%$ and $14 \%$, respectively, at one and two weeks after the third injection. 
The Tegner Lysholm score increased by $72 \%$ from the baseline to before the second injection, and then this increment remained the same also before the third injection. During the last two weeks it worsened by a $23 \%$ compared to the past two weeks. Anyway, if compared to the baseline, the one-month score increased by $33 \%$.

The KOOS score increased by $25 \%$ from the baseline to before the second injection, and by $10 \%$ from before the second injection to before the third injection. Then the score decreased during the last two weeks, by the $13 \%$ and $5 \%$ respectively if compared to the value reported before the third injection. Anyway, if compared to the baseline, the one-month score increased by $12 \%$.

The IKDC score increased by $18 \%$ from the baseline to before the second injection, and it remained the same also before the third injection. During the first week after the third injection, it decreased by $8 \%$, and then returned to the same score as baseline at two weeks after the third injection.

The mCKRS score increased by $18 \%$ from baseline to before the second injection, and by $15 \%$ from before the second to before the third injection. One week after the third injection, the score was the same as before the second injection, while the last score at two weeks after the third injection decreased by $12,5 \%$ compared with the past week. Anyway, if compared to the baseline, the one-month score increased by $3 \%$.

\section{DISCUSSION}

Professional soccer players are very susceptible to articular cartilage damage and early development of OA because of the repetitive high-level impact, stress and trauma due to running, jumping, acceleration, kicking and direction changing (Lane et al., 1993; Papalia et al., 2016). Hyaluronic acid for knee OA to relieve the pain caused by joint degeneration or injury represents a common therapeutic option method for most patients and athletes (Migliore et al., 2018; Wu et al., 2017). Anyway, the use of IA-HA in active sports players remains a controversial issue (Migliore et al., 2018).

In this study, we wanted to investigate the effects of IA-HA injections and oral collagen supplementation in a female soccer goalkeeper playing in Italian Women's Serie A league with secondary knee OA complaining of knee pain. This is, to our knowledge, the first report on the use of IA-HA and oral collagen supplementation in a female soccer player with knee OA, and one of the few articles that investigated the use of IA-HA for the recovery of active soccer players complaining of knee pain, adding some evidence on the efficacy and safety of this therapeutic option for active soccer players.

The results of our case-report showed that IA-HA injections and oral collagen supplementation showed some improvements on pain and functional impairment for secondary knee OA in a professional athlete, resulting in a rapid relief of symptoms in terms of pain and functionality of the affected knee and also in a rapid restart of sports activity. However, these benefits lasted for a very short period.

Our hypothesis is that after the first IA-HA injection, all scores improved since the athlete totally rested for three days, so this rest may have helped the pharmacologic effect of the HA. During the following weeks, the level of activity of the athlete increased and given the scores of the questionnaires, this probably reduced the HA effect. Then, during the first and the second week after the last IA-HA injection, all scores worsened, highlighting how the benefits of IA-HA injections lasted for a very short period of time. Anyway, these hypotheses could only be confirmed with further follow-ups of the athlete, since she was evaluated for just one month, so one limitation of the present study is the absence of a longer follow-up period. 


\section{CONCLUSION}

In our study, the use of IA-HA injections in a professional female soccer player with secondary knee OA seemed to be safe, allowed a rapid restart of sporting activity, but showed a very short-term effectiveness. Larger studies with longer follow-up times are needed to confirm the consistency of these findings.

\section{REFERENCES}

Agel, J., \& LaPrade, R. F. (2009). Assessment of differences between the modified Cincinnati and International Knee Documentation Committee patient outcome scores: A prospective study. The American Journal of Sports Medicine, 37(11), 2151-2157. https://doi.org/10.1177/0363546509337698

Aghamohammadi, D., Dolatkhah, N., Bakhtiari, F., Eslamian, F., \& Hashemian, M. (2020). Nutraceutical supplements in management of pain and disability in osteoarthritis: A systematic review and metaanalysis of randomized clinical trials. Scientific Reports, 10(1), 20892. https://doi.org/10.1038/s41598-020-78075-x

Aicale, R., Tarantino, D., \& Maffulli, N. (2018). Overuse injuries in sport: A comprehensive overview. Journal of Orthopaedic Surgery and Research, 13(1), 309. https://doi.org/10.1186/s13018-018-1017$\underline{5}$

Altman, R. D., Bedi, A., Karlsson, J., Sancheti, P., \& Schemitsch, E. (2016). Product Differences in Intraarticular Hyaluronic Acids for Osteoarthritis of the Knee. The American Journal of Sports Medicine, 44(8), 2158-2165. https://doi.org/10.1177/0363546515609599

Altman, R., Hackel, J., Niazi, F., Shaw, P., \& Nicholls, M. (2018). Efficacy and safety of repeated courses of hyaluronic acid injections for knee osteoarthritis: A systematic review. Seminars in Arthritis and Rheumatism, 48(2), 168-175. https://doi.org/10.1016/i.semarthrit.2018.01.009

Aune, K. T., Andrews, J. R., Dugas, J. R., \& Cain, E. L. (2014). Return to Play After Partial Lateral Meniscectomy in National Football League Athletes. The American Journal of Sports Medicine, 42(8), 1865-1872. https://doi.org/10.1177/0363546514535069

Ayhan, E., Kesmezacar, H., \& Akgun, I. (2014). Intraarticular injections (corticosteroid, hyaluronic acid, platelet rich plasma) for the knee osteoarthritis. World Journal of Orthopedics, 5(3), 351-361. https://doi.org/10.5312/wjo.v5.i3.351

Bahrami, M. H., Raeissadat, S. A., Cheraghi, M., Rahimi-Dehgolan, S., \& Ebrahimpour, A. (2020). Efficacy of single high-molecular-weight versus triple low-molecular-weight hyaluronic acid intraarticular injection among knee osteoarthritis patients. BMC Musculoskeletal Disorders, 21. https://doi.org/10.1186/s12891-020-03577-8

Baltzer, A. W. A., Moser, C., Jansen, S. A., \& Krauspe, R. (2009). Autologous conditioned serum (Orthokine) is an effective treatment for knee osteoarthritis. Osteoarthritis and Cartilage, 17(2), 152160. https://doi.org/10.1016/i.joca.2008.06.014

Bannuru, R. R., Schmid, C. H., Kent, D. M., Vaysbrot, E. E., Wong, J. B., \& McAlindon, T. E. (2015). Comparative effectiveness of pharmacologic interventions for knee osteoarthritis: A systematic review and network meta-analysis. Annals of Internal Medicine, 162(1), 46-54. https://doi.org/10.7326/M14-1231

Bannuru, R. R., Vaysbrot, E. E., Sullivan, M. C., \& McAlindon, T. E. (2014). Relative efficacy of hyaluronic acid in comparison with NSAIDs for knee osteoarthritis: A systematic review and meta-analysis. Seminars in Arthritis and Rheumatism, 43(5), 593-599. https://doi.org/10.1016/i.semarthrit.2013.10.002 
Cheng, O. T., Souzdalnitski, D., Vrooman, B., \& Cheng, J. (2012). Evidence-based knee injections for the management of arthritis. Pain Medicine (Malden, Mass.), 13(6), 740-753. https://doi.org/10.1111/j.1526-4637.2012.01394.x

Collins, N. J., Misra, D., Felson, D. T., Crossley, K. M., \& Roos, E. M. (2011). Measures of Knee Function. Arthritis Care \& Research, 63(0 11), S208-S228. https://doi.org/10.1002/acr.20632

Concoff, A., Sancheti, P., Niazi, F., Shaw, P., \& Rosen, J. (2017). The efficacy of multiple versus single hyaluronic acid injections: A systematic review and meta-analysis. BMC Musculoskeletal Disorders, 18(1), 542. https://doi.org/10.1186/s12891-017-1897-2

Creamer, P., Sharif, M., George, E., Meadows, K., Cushnaghan, J., Shinmei, M., \& Dieppe, P. (1994). Intra-articular hyaluronic acid in osteoarthritis of the knee: An investigation into mechanisms of action. Osteoarthritis and Cartilage, 2(2), 133-140. https://doi.org/10.1016/s1063-4584(05)80063-9

Crichton, N. (2001). Visual analogue scale (VAS). Journal of Clinical Nursing, 10. https://doi.org/10.1007/978-3-211-89836-9_1450

da Costa, B. R., Hari, R., \& Jüni, P. (2016). Intra-articular Corticosteroids for Osteoarthritis of the Knee. JAMA, 316(24), 2671-2672. https://doi.org/10.1001/jama.2016.17565

Drawer, S., \& Fuller, C. W. (2001). Propensity for osteoarthritis and lower limb joint pain in retired professional soccer players. British Journal of Sports Medicine, 35(6), 402-408. https://doi.org/10.1136/bjsm.35.6.402

Dvorak, J. (2011). Osteoarthritis in football: FIFA/F-MARC approach. British Journal of Sports Medicine, 45(8), 673-676. https://doi.org/10.1136/bjsm.2011.083584

Elleuch, M. H., Guermazi, M., Mezghanni, M., Ghroubi, S., Fki, H., Mefteh, S., Baklouti, S., \& Sellami, S. (2008). Knee osteoarthritis in 50 former top-level soccer players: A comparative study. Annales De Readaptation Et De Medecine Physique: Revue Scientifique De La Societe Francaise De Reeducation Fonctionnelle De Readaptation Et De Medecine Physique, 51(3), 174-178. https://doi.org/10.1016/i.annrmp.2008.01.003

Gouttebarge, V., Inklaar, H., \& Frings-Dresen, M. H. (2014). Risk and consequences of osteoarthritis after a professional football career: A systematic review of the recent literature. The Journal of Sports Medicine and Physical Fitness, 54(4), 494-504.

Guadagna, S., Barattini, D. F., Pricop, M., \& Rosu, S. (2018). Oral hyaluronan for the treatment of knee osteoarthritis: A systematic review. Progress in Nutrition, 20(4), 537-544. https://doi.org/10.23751/pn.v20i4.7581

He, W.-W., Kuang, M.-J., Zhao, J., Sun, L., Lu, B., Wang, Y., Ma, J.-X., \& Ma, X.-L. (2017). Efficacy and safety of intraarticular hyaluronic acid and corticosteroid for knee osteoarthritis: A meta-analysis. International Journal of Surgery (London, England), 39, 95-103. https://doi.org/10.1016/j.ijsu.2017.01.087

Honvo, G., Lengelé, L., Charles, A., Reginster, J.-Y., \& Bruyère, O. (2020). Role of Collagen Derivatives in Osteoarthritis and Cartilage Repair: A Systematic Scoping Review With Evidence Mapping. Rheumatology and Therapy, 7(4), 703-740. https://doi.org/10.1007/s40744-020-00240-5

Hummer, C. D., Angst, F., Ngai, W., Whittington, C., Yoon, S. S., Duarte, L., Manitt, C., \& Schemitsch, E. (2020). High molecular weight Intraarticular hyaluronic acid for the treatment of knee osteoarthritis: A network meta-analysis. BMC Musculoskeletal Disorders, 21(1), 702. https://doi.org/10.1186/s12891-020-03729-w

Irrgang, J. J., Anderson, A. F., Boland, A. L., Harner, C. D., Kurosaka, M., Neyret, P., Richmond, J. C., \& Shelborne, K. D. (2001). Development and validation of the international knee documentation committee subjective knee form. The American Journal of Sports Medicine, 29(5), 600-613 https://doi.org/10.1177/03635465010290051301 
Krajnc, Z., Vogrin, M., Recnik, G., Crnjac, A., Drobnic, M., \& Antolic, V. (2010). Increased risk of knee injuries and osteoarthritis in the non-dominant leg of former professional football players. Wiener Klinische Wochenschrift, 122 Suppl 2, 40-43. https://doi.org/10.1007/s00508-010-1341-1

Lane, N. E., Michel, B., Bjorkengren, A., Oehlert, J., Shi, H., Bloch, D. A., \& Fries, J. F. (1993). The risk of osteoarthritis with running and aging: A 5-year longitudinal study. The Journal of Rheumatology, 20(3), 461-468.

Liu, X., Machado, G. C., Eyles, J. P., Ravi, V., \& Hunter, D. J. (2018). Dietary supplements for treating osteoarthritis: A systematic review and meta-analysis. British Journal of Sports Medicine, 52(3), 167175. https://doi.org/10.1136/bjsports-2016-097333

Maheu, E., Bannuru, R. R., Herrero-Beaumont, G., Allali, F., Bard, H., \& Migliore, A. (2019). Why we should definitely include intra-articular hyaluronic acid as a therapeutic option in the management of knee osteoarthritis: Results of an extensive critical literature review. Seminars in Arthritis and Rheumatism, 48(4), 563-572. https://doi.org/10.1016/j.semarthrit.2018.06.002

Marks, R. (2020). Collagen Supplements and Osteoarthritis Pain: How Persuasive is the Evidence? 11, 28-39.

Marshall, K. W. (2003). Intra-articular hyaluronan therapy. Foot and Ankle Clinics, 8(2), 221-232. https://doi.org/10.1016/S1083-7515(03)00046-9

McAlindon, T. E., Bannuru, R. R., Sullivan, M. C., Arden, N. K., Berenbaum, F., Bierma-Zeinstra, S. M., Hawker, G. A., Henrotin, Y., Hunter, D. J., Kawaguchi, H., Kwoh, K., Lohmander, S., Rannou, F., Roos, E. M., \& Underwood, M. (2014). OARSI guidelines for the non-surgical management of knee $\begin{array}{llll}\text { osteoarthritis. Osteoarthritis } \quad \text { and } & \text { Cartilage, }\end{array}$ https://doi.org/10.1016/j.joca.2014.01.003

Migliore, A., Giannini, S., Bizzi, E., Massafra, U., Cassol, M., Abilius, M. J. M., \& Boni, G. (2018). Use of viscosupplementation for the recovery of active football players complaining of knee pain. Open Access Journal of Sports Medicine, 10, 11-15. https://doi.org/10.2147/OAJSM.S164693

Miller, L. E., \& Block, J. E. (2013). US-Approved Intra-Articular Hyaluronic Acid Injections are Safe and Effective in Patients with Knee Osteoarthritis: Systematic Review and Meta-Analysis of Randomized, Saline-Controlled Trials. Clinical Medicine Insights. Arthritis and Musculoskeletal Disorders, 6, 5763. https://doi.org/10.4137/CMAMD.S12743

Mitsou, A., Vallianatos, P., Piskopakis, N., \& Maheras, S. (1990). Anterior cruciate ligament reconstruction by over-the-top repair combined with popliteus tendon plasty. The Journal of Bone and Joint Surgery. British Volume, 72(3), 398-404. https://doi.org/10.1302/0301$\underline{620 X .72 B 3.2341436}$

Moreland, L. W. (2003). Intra-articular hyaluronan (hyaluronic acid) and hylans for the treatment of osteoarthritis: Mechanisms of action. Arthritis Research \& Therapy, 5(2), 54-67. https://doi.org/10.1186/ar623

Nouri, F., Raeissadat, S. A., Eliaspour, D., Rayegani, S. M., Rahimi, M. S., \& Movahedi, B. (2019). Efficacy of High-Power Laser in Alleviating Pain and Improving Function of Patients With Patellofemoral Pain Syndrome: A Single-Blind Randomized Controlled Trial. Journal of Lasers in Medical Sciences, 10(1), 37-43. https://doi.org/10.15171/jlms.2019.06

Noyes, F. R., Barber, S. D., \& Mooar, L. A. (1989). A rationale for assessing sports activity levels and limitations in knee disorders. Clinical Orthopaedics and Related Research, 246, 238-249. https://doi.org/10.1097/00003086-198909000-00034

Papalia, R., Zampogna, B., Russo, F., Vasta, S., Tirindelli, M. C., Nobile, C., Di Martino, A. C., Vadalà, G., \& Denaro, V. (2016). Comparing hybrid hyaluronic acid with PRP in end career athletes with degenerative cartilage lesions of the knee. Journal of Biological Regulators and Homeostatic Agents, 30(4 Suppl 1), 17-23. 
Raeissadat, S. A., Rayegani, S. M., Sedighipour, L., Bossaghzade, Z., Abdollahzadeh, M. H., Nikray, R., \& Mollayi, F. (2018). The efficacy of electromyographic biofeedback on pain, function, and maximal thickness of vastus medialis oblique muscle in patients with knee osteoarthritis: A randomized clinical trial. Journal of Pain Research, 11, 2781-2789. https://doi.org/10.2147/JPR.S169613

Raeissadat, S. A., Tabibian, E., Rayegani, S. M., Rahimi-Dehgolan, S., \& Babaei-Ghazani, A. (2018). An investigation into the efficacy of intra-articular ozone (02-O3) injection in patients with knee osteoarthritis: A systematic review and meta-analysis. Journal of Pain Research, 11, 2537-2550. https://doi.org/10.2147/JPR.S175441

Reid, M. C. (2013). Viscosupplementation for osteoarthritis: A primer for primary care physicians. Advances in Therapy, 30(11), 967-986. https://doi.org/10.1007/s12325-013-0068-6

Roos, E. M., Roos, H. P., Lohmander, L. S., Ekdahl, C., \& Beynnon, B. D. (1998). Knee Injury and Osteoarthritis Outcome Score (KOOS)-Development of a self-administered outcome measure. The Journal of Orthopaedic and Sports Physical Therapy, 28(2), 88-96. https://doi.org/10.2519/jospt.1998.28.2.88

Roque, V., Agre, M., Barroso, J., \& Brito, I. (2013). Managing knee ostheoarthritis: Efficacy of hyaluronic acid injections. Acta Reumatologica Portuguesa, 38(3), 154-161.

Sánchez, M., Fiz, N., Azofra, J., Usabiaga, J., Aduriz Recalde, E., Garcia Gutierrez, A., Albillos, J., Gárate, R., Aguirre, J. J., Padilla, S., Orive, G., \& Anitua, E. (2012). A randomized clinical trial evaluating plasma rich in growth factors (PRGF-Endoret) versus hyaluronic acid in the short-term treatment of symptomatic knee osteoarthritis. Arthroscopy: The Journal of Arthroscopic \& Related Surgery: Official Publication of the Arthroscopy Association of North America and the International Arthroscopy Association, 28(8), 1070-1078. https://doi.org/10.1016/j.arthro.2012.05.011

Sirico F, Ricca F, DI Meglio F, Nurzynska D, Castaldo C, Spera R, Montagnani S. Local corticosteroid versus autologous blood injections in lateral epicondylitis: meta-analysis of randomized controlled trials. Eur J Phys Rehabil Med. 2017 Jun;53(3):483-491. https://doi.org/10.23736/S1973$\underline{9087.16 .04252-0}$

Takeda, H., Nakagawa, T., Nakamura, K., \& Engebretsen, L. (2011). Prevention and management of knee osteoarthritis and knee cartilage injury in sports. British Journal of Sports Medicine, 45(4), 304309. https://doi.org/10.1136/bjsm.2010.082321

Tarantino, D., \& Brancaccio, P. (2019, December 30). Sports Injury Prevention: A Concise Review. Pharmacologyonline, 1-11.

Tasciotaoglu, F., \& Oner, C. (2003). Efficacy of intra-articular sodium hyaluronate in the treatment of knee osteoarthritis. Clinical Rheumatology, 22(2), 112-117. https://doi.org/10.1007/s10067-002$\underline{0690-1}$

Tegner, Y., \& Lysholm, J. (1985). Rating systems in the evaluation of knee ligament injuries. Clinical Orthopaedics and Related Research, 198, 43-49. https://doi.org/10.1097/00003086-19850900000007

Vazquez, P., Tovilla-Zarate, C.A., Hernández-Díaz, Y., González-Castro, T., Juárez-Rojop, I., Narváez, L., Bermudez-Ocaña, D., Barjau-Madrígal, H., Legorreta-Ramírez, G. (2019). Short-Term Therapeutic Effects of Ozone in the Management of Pain in Knee Osteoarthritis: A Meta-Analysis. PM\&R. 11. https://doi.org/10.1002/pmrj.12088

Wu, C.-S., Cheng, H.-Y., Hsu, P.-F., Kao, Y.-H., \& Kuo, S. M. (2017). Evaluation of the Therapeutic Effects of Hyaluronic Acid Injections on Football Players' Articular Cartilage Using an Immunochromatographic Urine Strip. Journal of Medical and Biological Engineering, 37(2), 268-275. https://doi.org/10.1007/s40846-017-0221-9 
Tarantino, et al. / Hyaluronic acid injections \& collagen supplementation for knee OA JOURNAL OF HUMAN SPORT \& EXERCISE

\section{(c) (1) (9)}

This work is licensed under a Attribution-NonCommercial-NoDerivatives 4.0 International (CC BY-NC-ND 4.0). 